\title{
EXCLUSÃO SOCIAL E VULNERABILIDADES NO TRABALHO DE CRIANÇAS E ADOLESCENTES CATADORES DE MATERIAL RECICLÁVEL
}

\author{
LUCIMARE FerRaZ \\ Universidade Comunitária da Região de Chapecó (Unochapeco), \\ Chapecó, Santa Catarina, Brasil \\ Mara Helena de Andrea Gomes \\ Universidade Federal de São Paulo (Unifesp), São Paulo, Brasil \\ CÁsSIO SILVERA \\ Universidade Federal de São Paulo (Unifesp), São Paulo, Brasil
}

Resumo: O objetivo desse artigo é analisar o cotidiano de trabalho de crianças e adolescentes catadoras de material reciclável com base nos conceitos de vulnerabilidade e exclusão social. Trata-se de um estudo qualitativo com a participação de importantes atores institucionais envolvidos em ações sociais, jurídicas e de apoio, e, também, junto a um grupo de crianças e adolescentes e seus familiares na cidade de Chapecó, estado de Santa Catarina. Conclui-se que trabalho de coleta de material reciclável constitui uma forma de inserção social que, ao mesmo tempo, expõe crianças e adolescentes a riscos de todo tipo, constituindo processos de vulnerabilidade nessas faixas etárias.

Palavras-chave: Exclusão social. Vulnerabilidades. Trabalho infantil. Catadores de material reciclável. 
INTRODUÇÃO

A situação econômica frágil e precária conduz muitas famílias a enfrentar a pobreza por meio do trabalho de seus filhos, crianças ou adolescentes ainda. Souza (2001) explica que a precariedade, a instabilidade das ocupações e o reduzido nível de renda dos adultos configuram uma situação em que o ingresso precoce de crianças no trabalho torna-se uma necessidade para assegurar a subsistência da família. Por conseguinte, "quanto menor a renda familiar dos adultos, maior a proporção da contribuição de crianças e adolescentes à renda familiar total, maior a exclusão escolar de adolescentes" (FACCHINl et al. 2003, p 953).

Embora o trabalho infantil alcance uma resposta econômica imediata para assegurar a sobrevivência das famílias, a estratégia da utilização da força de trabalho infantil por famílias de baixa renda reveste-se de elevado custo social com o passar do tempo, na medida em que perpetua a pobreza e a desigualdade (KASSOUF, 2007). A inclusão de crianças e adolescentes no universo de trabalho adulto é um fenômeno de natureza complexa com dimensões relacionadas às situações de pobreza, desigualdade e exclusão social.

Para boa parte das famílias de baixa renda o trabalho dos filhos, crianças ou adolescentes, não é uma opção, mas uma necessidade frente às dificuldades financeiras e se veem conduzidas a impeli-los ao mundo do trabalho adulto. Vale destacar que aqueles que hoje estão fora da escola ou não estudam satisfatoriamente porque trabalham, dificilmente atenderão, quando adultos, as exigências do mercado de trabalho formal, tendo como opção de renda atividades de trabalho informal, como o de catador de material reciclável.

Segundo Bosi (2008), os catadores constituíram trajetórias ocupacionais marcadas pela precariedade das ocupações, uma vez que parte desses catadores nasceu e cresceu no campo e o aprendizado para o trabalho se constituiu nos afazeres da agricultura, da suinocultura e da pecuária. Quando migram para as cidades acabam desempenhando ocupações que não exigem qualificação profissional. Ao referirem-se ao processo histórico de exclusão dos catadores de lixo, Cavalcante e Franco (2007) ressaltam que a exploração da força de trabalho dos catadores possui raízes históricas no êxodo rural. Uma vez nas cidades, a vida urbana proporciona uma inclusão precária, à margem dos mercados formais de trabalho, configurando o que Martins qualifica como inclusão perversa (MARTINS, 1997). 
A literatura consultada permite perceber que os termos desigualdade, pobreza e exclusão muitas vezes são citados como sinônimos ou como indissociáveis, motivo pelo qual preferimos considerá-los numa perspectiva de entrelaçamento, já que não existe pobreza sem desigualdade nem desigualdade sem exclusão. Esse cenário marcado por processos de exclusão social, acentuados níveis de pobreza e trabalho infantil, acaba por gerar situações de vulnerabilidade entre as crianças e adolescentes catadores.

Para Castel (1998, p. 26), exclusão social designa estados de privação. O autor aborda a perda do status social como um processo de "desfiliação social, em que a noção pertence ao mesmo campo semântico que a dissociação, a desqualificação ou a invalidação social". A desfiliação é resultado da crise na sociedade salarial decorrente da ruptura dos vínculos de filiação institucionais. Sua análise possibilitou compreender as transformações do Welfare State no contexto dos países europeus em fins do século XX, considerando, portanto, a inclusão/exclusão efetivada pelas políticas sociais e pelo trabalho, particularmente na França.

De modo mais próximo à concepção de Castel, para Sawaia (1999), a exclusão é processo complexo, multifacetado, de dimensões materiais, políticas, relacionais e subjetivas, uma vez que a mesma sociedade que exclui o indivíduo e/ou grupos, inclui-nos em outra ordem social de desigualdade. Segundo a autora, "a dialética exclusão e inclusão pertence à mesma substância, e forma um par indissociável, que se constitui na própria relação" (SAWAIA, 1999, p. 107-108). Com apoio em Foucault, a autora destaca que "a inclusão social é o processo de disciplinarização dos excluídos, portanto, um processo de controle social e manutenção da ordem na desigualdade social". (SAWAIA, 1999, p. 107-108)

Essa perspectiva também é assumida por Escorel (1999, p. 67), ao tomar o cuidado de chamar atenção para o conteúdo do termo (e não conceito) "exclusão social" para indicar "ao mesmo tempo um processo e um estado". Processo, porque se trata do movimento social que exclui; e estado, devido ao resultado final deste movimento, que é a própria exclusão. A autora faz questão de também destacar que a exclusão social é uma expressão que pode "designar toda situação ou condução social de carência, dificuldade de acesso, segregação, discriminação, vulnerabilidade e precariedade em qualquer âmbito [pois] a exclusão não é somente de bens materiais, [uma vez] que esta privação desqualifica seu portador" (p. 23; 81).

A exclusão pode ser considerada ainda como uma categoria cognitiva que visa a caracterizar o status social de indivíduos que pertencem 
à sociedade, mas em condição de inferioridade. Para Lavinas (2003), este termo tem uma conotação negativa, pois demonstra uma deficiência na integração entre sistema produtivo e de consumo, na qual a tônica é dada pelo empobrecimento nas relações sociais. Enquanto a pobreza é o resultado da desigualdade imposta pelo mercado de trabalho e está fortemente associada à dinâmica macroeconômica e ao sistema de proteção social, a exclusão significa a ruptura de vínculos sociais e pode ser enfrentada através de estratégias locais de inclusão.

O trabalho de coleta de material reciclável constitui uma alternativa de inclusão social que, como outras modalidades de trabalho, expõe os trabalhadores a risco de vários tipos. O conceito de vulnerabilidade é o eixo temático desta reflexão sobre o cotidiano de trabalho das crianças e adolescentes catadoras, permitindo problematizar a noção de exclusão social da faixa etária infantojuvenil inserida nesse processo.

Diante da tradicional abordagem comportamentalista relacionada às estratégias exclusivamente individuais de redução de risco, Ayres (1999) propõe o conceito de vulnerabilidade para avaliar as diferentes características individuais e sociais, julgadas relevantes nas situações de exposição a um fator de risco ou de menor chance de proteção. Para Ayres (1999), conceitualmente a vulnerabilidade tem origem no campo de advocacia internacional pelos Direitos Humanos. Nessa área, o termo nomeia grupos ou indivíduos fragilizados, jurídica ou politicamente, na promoção, proteção ou garantia dos seus direitos de cidadania, estando vinculado a situações de iniquidade e desigualdade social, bem como de enfrentamentos relacionados a indivíduos, grupos e coletividade.

Quando se trata de vulnerabilidade infantojuvenil, devemos levar em consideração que essa faixa transcende seu tamanho, força ou idade, mas liga-se às práticas sociais. Outrossim, "pensar a vulnerabilidade das crianças e adolescentes significa considerar sua limitação e, ao mesmo tempo, as condições de sua superação. Isso requer valorizar não apenas a qualidade dos relacionamentos, mas também dos espaços públicos que são atravessados pela infância". (SIERRA; MESQUITA, 2006, p. 151).

Acreditamos que a vulnerabilidade do catador infantojuvenil de material reciclável está intimamente condicionada aos processos sociais de desigualdade, pobreza e exclusão. Diante desse alargamento do quadro de referência, não podemos deixar de problematizar as noções constitutivas da situação que pretendemos investigar, com o objetivo de analisar o cotidiano 
de trabalho de crianças e adolescentes catadoras de material reciclável sob a ótica da vulnerabilidade e da exclusão social dessa população.

\section{Metodologia}

Este estudo foi realizado no município de Chapecó, estado Santa Catarina e contou com a colaboração de diversos sujeitos, devido ao caráter de investigação. Havíamos previsto somente a participação de crianças e adolescentes catadores de lixo, de seus pais e dos profissionais da área da saúde, da educação e da assistência social atuantes nas áreas citadas anteriormente. Porém, durante o processo investigativo ponderamos a necessidade de incluir outros sujeitos/informantes para a uma melhor compreensão do universo em estudo, conforme mostra o quadro 1.

Quadro 1 - Apresentação dos participantes do estudo sobre a vulnerabilidade da criança e adolescente catador de material reciclável no município de Chapecó-SC.

\begin{tabular}{ll}
\hline Público & Participantes \\
Famílias & 24 famílias: 15 pais e 24 mães \\
Infantojuvenis & Duas crianças e 20 adolescentes \\
Setor da Saúde & $\begin{array}{l}\text { Três coordenadores da estratégia saúde } \\
\text { da Família (duas enfermeiras e uma ci- } \\
\text { rurgiã Dentista) }\end{array}$ \\
Setor da Educação & $\begin{array}{l}\text { Três gestores educacionais } \\
\text { (duas mulheres e um homem) }\end{array}$ \\
Setor da Assistência Social & $\begin{array}{l}\text { Cinco assistentes sociais (Centro de } \\
\text { Referência de Assistência Social - CRAS) }\end{array}$ \\
Conselho tutelar & Dois conselheiros \\
$\begin{array}{l}\text { Fundação de ação social de } \\
\text { Chapecó-FASC }\end{array}$ & $\begin{array}{l}\text { A gerente do programa da criança e } \\
\text { do adolescente e o coordenador do } \\
\text { programa trabalho e renda. }\end{array}$ \\
$\begin{array}{l}\text { Fundação de Meio Ambiente } \\
\text { de Chapecó (FUNDEMA) }\end{array}$ & $\begin{array}{l}\text { A Diretora da Fundação de } \\
\text { Meio Ambiente de Chapecó }\end{array}$ \\
$\begin{array}{l}\text { Centro de Referência Especializada } \\
\text { de Assistência Social (CREAS) }\end{array}$ & $\begin{array}{l}\text { A assistente social do Centro de Refe- } \\
\text { rência Especializado de Assistência So- } \\
\text { cial - CREAS. }\end{array}$ \\
Informante-chave & $\begin{array}{l}\text { Um ex-catador adulto } \\
\mathbf{6 4} \text { entrevistados }\end{array}$ \\
\hline
\end{tabular}

Com o intuito de descrever a realidade levando em conta essas pessoas e instâncias relacionadas ao objetivo proposto, aplicamos técnicas variadas 
de coleta de informações, como entrevista semiestruturada, observações e grupo focal. Vale destacar que o desenvolvimento das técnicas aconteceu de forma interativa, possibilitando assim a retroalimentação dos dados coletados.

As entrevistas seguiram um roteiro de questões semiabertas e o grupo focal foi realizado com nove crianças e adolescentes catadores. Os participantes foram convidados a integrar o grupo por meio de convites entregues em seus domicílios. Foram dois encontros com o mesmo grupo, em dois sábados consecutivos. As observações ocorriam durante as entrevistas, com especial atenção para o local de moradia, o veículo usado para a coleta e o local de depósito de materiais coletados.

O primeiro encontro do grupo focal iniciou-se com a nossa apresentação (pesquisadora, acadêmico de enfermagem e do serviço social e de uma professora de enfermagem), das duas crianças e dos sete adolescentes que vieram participar da atividade. Após as apresentações, o grupo de crianças foi dividido em subgrupos de três participantes. Nesses pequenos grupos conduzidos por um monitor, as crianças relataram o cotidiano de trabalho na catação de material reciclável. Ao término dessa etapa, houve um momento de recreação com a oferta de lanches para, em seguida, reunir o grande grupo em uma roda para discutir coletivamente o tema: "o cotidiano de trabalho".

No segundo encontro do grupo focal participaram seis adolescentes e somente uma criança, mas a dinâmica se manteve primeiro em pequenos grupos, depois a socialização e debate no grande grupo. Nesse dia o tema posto em análise e discussão foi: "acidentes de trabalho e seus fatores de riscos."

Os debates do grupo foram registrados por meio de gravação digital mediante à autorização dos participantes, e por anotações, a fim de garantir o registro das expressões não verbalizadas, como o silêncio ou frases satirizadas. O uso associado dessas duas formas visou a minimizar problemas de falhas na gravação, chiados, conversas paralelas e outros imprevistos capazes de prejudicar o registro dos conteúdos.

As entrevistas foram realizadas no ambiente de trabalho dos profissionais citados no quadro 1 e nos domicílios dos pais das crianças e adolescentes. Quanto às observações, essas ocorriam durante as entrevistas. Era observado o local de moradia, o veículo usado para a coleta e o depósito de materiais. Essas informações foram anotadas num diário de campo.

A interpretação das informações foi realizada pela técnica de Análise de Conteúdo, que congrega técnicas de análise visando a obter, por proce- 
dimentos sistemáticos e objetivos, a descrição do conteúdo das mensagens e indicadores de modo a inferir conhecimentos relativos às condições de produção/recepção dessas mensagens (BARDIN, 2009).

O projeto de pesquisa foi aprovado pelo Comitê de Ética de Pesquisa da Universidade Federal de São Paulo-UNIFESP (protocolo número 1015/07). Os protocolos usados nesta pesquisa estão rigorosamente de acordo com a Resolução 10/196/96, Cap. VI, VI-5, do Conselho Nacional de Saúde/Ministério da Saúde.

\section{RESULTADO E DISCUSSÃO}

O trabalho infantil, as práticas, os riscos, a vulnerabilidade, o significado, as dimensões e concepções desse universo, são questões importantes de serem desvendadas sob a ótica da vulnerabilidade. Assim, para compreender a dinâmica social das crianças e adolescentes envolvidos na catação de lixo significa, igualmente, que"pensar a vulnerabilidade das crianças e adolescentes significa considerar sua limitação e, ao mesmo tempo, as condições de sua superação [...] isso requer valorizar os espaços públicos que são atravessados pela infância" (SIERRA; MESQUITA, 2006, p. 151).

Neste artigo, analisamos a vulnerabilidade do universo das crianças e adolescentes catadores sob as óticas ocupacional e social, segundo os sujeitos envolvidos no trabalho e na proteção desses infantojuvenis.

\section{A VULNERABILIDADE OCUPACIONAL DAS CRIANÇAS E ADOLESCENTES CATADORES}

Os vários riscos de acidentes e de danos à saúde que observamos ao longo da pesquisa permitem afirmar que as crianças e adolescentes catadores de lixo estão em grave situação de vulnerabilidade ocupacional. $O$ fato de desconhecerem esses riscos também é fator agravante, uma vez que não evitam os perigos que permeiam suas atividades laborais e também pudemos verificar que não possuem habilidades requeridas para enfrentar os riscos, tampouco para cuidar e tratar dos danos sofridos.

A visão naturalizada e/ou resignada que os pais dos pequenos catadores possuem sobre os perigos aos quais seus filhos estão expostos dificulta ainda mais o desenvolvimento de propostas de condutas de prevenção e atenção à saúde das crianças e adolescentes. 
Quanto aos profissionais que atuam na rede de proteção à criança e ao adolescente, embora percebam os perigos e fatores de riscos envolvidos no trabalho infantil, nenhuma instituição com a qual tivemos contato relatou algum trabalho educativo e preventivo direcionado à população de catadores. Portanto, a vulnerabilidade existente é reproduzida ao longo dos anos, sem que víssemos indícios de desejo de superá-la.

Na dimensão individual da vulnerabilidade, a vivência de cada pessoa está relacionada com aspectos da sua constituição física e até a maneira como "gerencia" seu cotidiano (AYRES; PAIVA; FRANÇA JÚNIOR, 2012). Os elementos da vulnerabilidade individual precisam ser analisados nas condições ambientais e culturais em que as condutas ocorrem, "bem como com o grau de consciência que essas pessoas têm sobre tais comportamentos e ao efetivo poder que podem exercer para transformá-los" (MEYER, et al. 2006, p. 1339). No entanto, é muito importante salientar que as possibilidades de mudança de comportamentos e práticas "não dependem apenas da vontade individual, [...] as pessoas respondem à transformação das práticas não no plano estrito da individualidade privada, mas como sujeitos sociais, como agentes da esfera pública da vida social" (AYRES, et al. 2003, p. 129).

Considerando que, uma vez que as desconhecem, esses trabaIhadores infantis têm poucas condições de enfrentamento individual dos riscos ocupacionais, a vulnerabilidade vivenciada por eles deve também ser considerada como expressão de exclusão social, uma vez que a capacidade de confrontar com essas condições é diminuída (PALMA; MATTOS, 2001; NAKAMURA et al. 2009). Como agravante, salientamos que essas crianças e adolescentes trabalhadoras não têm uma rede de proteção tal como é oficialmente concebida, constituída pela família, por profissionais da saúde, da educação e outros setores, para Ihes assegurar salubridade ocupacional e até domiciliar.

A figura 1 apresenta os fatores de desproteção social que contribuem para o aumento da vulnerabilidade desses infantojuvenis. 


\section{Baixa}

consideração dos

riscos

ocupacionais

pelos pais
Fragilidades nas

orientações dos pais

para enfretamento

dos riscos

ocupacionais
Ínfima atuação

dos atores sociais

na proteção aos

riscos

ocupacionais

Inexistência de

políticas públicas

de proteção aos catadores

Figura 1 - Apresentação dos fatores promotores da vulnerabilidade ocupacional de crianças e adolescentes catadoras de material reciclável.

Os fatores sociais, envolvidos no processo de vulnerabilidade ocupacional desses trabalhadores infantis, dizem respeito ao fato desta população não ser assistida e cuidada pelos seus responsáveis. Destacamos que não há políticas nacionais, regionais ou locais direcionadas a prevenção de acidentes no trabalho dos catadores, adultos ou crianças. Por isso é necessário repensar a proteção a essas crianças e adolescentes considerando, antes de tudo, que essa atividade é trabalho. Na qualidade de trabalho como condição de sobrevivência é que se deve pensar, de maneira articulada, os "riscos, causalidades e determinações, trazendo a saúde, assim como a possibilidade de adoecer, para o campo da vida real, para o mundo dos sujeitos em relação, no qual esses processos ganham sentidos singulares" (MEYER et al. 2006, p. 1341)

\section{A VULNERABILIDADE SOCIAL DAS CRIANÇAS E ADOLESCENTES CATADORES}

A dimensão da vulnerabilidade social aponta o risco de comprometimento físico/orgânico (por acidentes, posturas inadequadas, esforços físicos demasiados, entre outros) que o trabalho precoce pode ocasionar na vida profissional, atual e futura, dessas crianças e adolescentes.

Quanto ao acesso ao conhecimento proporcionado pelo ensino formal, a própria rotina de trabalho realizado nas ruas, ao relento e a longas distâncias tanto das moradias como da escola, se encarrega de excluí-los. Além disso, não são benquistos pelos servidores encarregados, que alegam a sujeira e o mau cheiro das crianças, quando não as maltratam. Esses impedimentos 
agravam o processo de exclusão e desqualificação profissional, impedindo o acesso ao saber que, associado à possibilidade de inserção no mercado formal de trabalho e a todos os direitos provenientes desta condição, intensificam as desigualdades sociais e o crescimento da pobreza.

Há também que considerar a violência urbana como mais um indicador de vulnerabilidade, por sua presença ao longo da jornada laboral dos catadores na forma de acidentes de trânsito, de maus tratos e agressões, violência psíquica e exploração do trabalho.

A própria inexistência de políticas públicas como seguridade social, proteção ocupacional e outras formas de assistência voltadas à proteção e superação da miséria e da pobreza enfrentada por essa população, configura esse trabalho precário de coleta e separação do lixo em material reciclável como a alternativa mais viável de sobrevivência. Desde modo mantêm-se o ciclo perverso da perpetuação da pobreza e manutenção da exclusão social.

A figura 2 ilustra os riscos, identificado no estudo, que expõem crianças e adolescentes catadores de lixo à vulnerabilidade social.

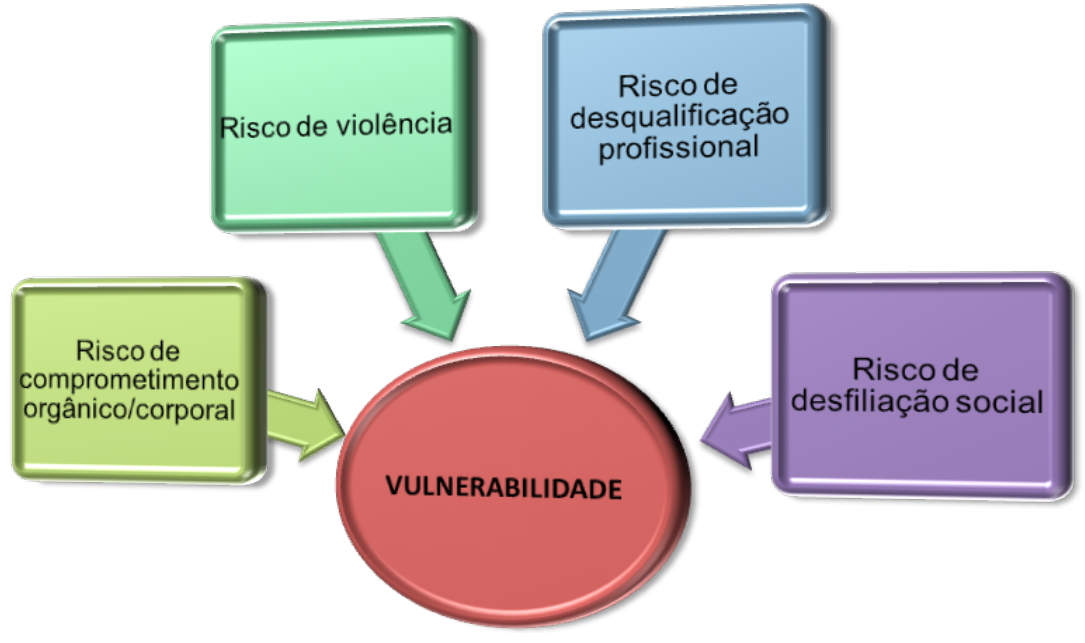

Figura 2 - Apresentação da vulnerabilidade social segundo os riscos pelos quais as crianças e adolescentes catadores de material reciclável estão expostas.

Considerando as condições de vida e sobrevida das famílias do estudo, o trabalho infantil na coleta e separação do lixo é socialmente considerado um meio de abrandar a vulnerabilidade social destas crianças e adolescentes. 
Em muitos casos a catação os afasta da violência presente em suas casas e na comunidade em que vivem. Quando estão na coleta, na companhia de seus pais, é menor a probabilidade (o risco) de se exporem a situações de contravenções como roubos e tráfico de drogas.

$\mathrm{Na}$ atividade laboral desenvolvem habilidades de comunicação, negociação e socialização com a população com a qual entram em contato. Não se pode afirmar que se essas crianças e adolescentes não estivessem trabalhando seriam menos vulneráveis à desfiliação social.

A figura 3 apresenta o processo de exposição e de proteção do trabalho infantil na coleta e separação de material reciclável.

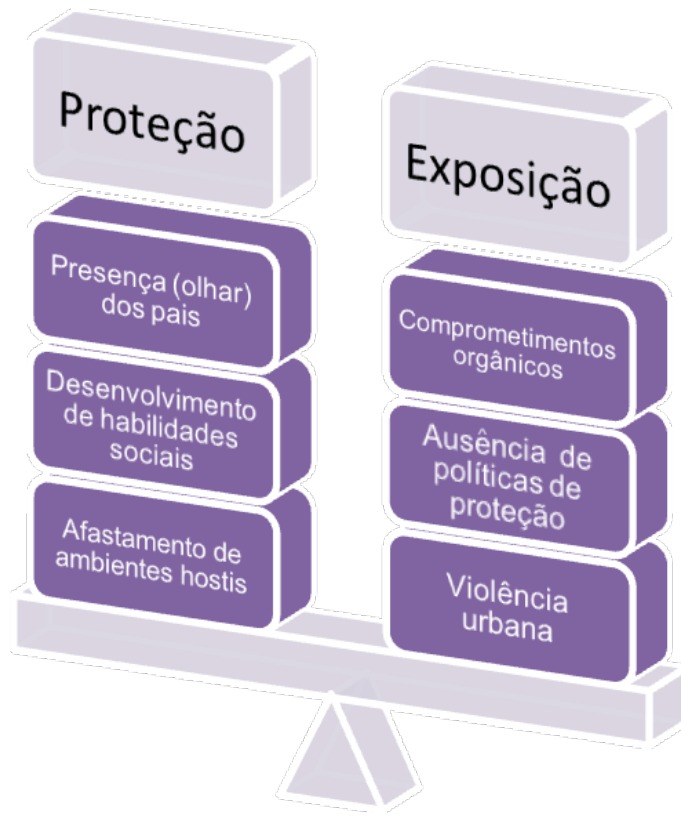

Figura 3 - Apresentação dos fatores de proteção e exposição envolvidos no processo de vulnerabilidade das crianças e adolescentes catadoras de material reciclável, Chapecó-SC.

As crianças e adolescentes desse estudo estão/são vulneráveis porque exercem uma atividade laboral perigosa e insalubre com pouco conhecimento sobre os modos de evitar acidentes ocupacionais. Ao trabalharem, distanciam-se de experiências essenciais da infância e da juventude (como brincar e estudar adequadamente), sem necessidade de assumirem respon- 
sabilidades impróprias ao seu estágio de desenvolvimento cognitivo-social. Por outro lado, nossa observação nos conduz a acreditar que nas condições de vida dessas famílias, o trabalho precoce, junto ao pai ou à mãe, pode ser uma forma de proteção não encontrada nem em instituições que deveriam protegê-las, como as creches e escolas que contatamos.

\section{CONSIDERAÇÕES FINAIS}

Os resultados do estudo evidenciam que essas crianças e adolescentes são vulneráveis nos aspectos relacionados às atividades ocupacionais e sociais. No entanto, considerando seus contextos de vida - a falta constante de recursos materiais, a precariedade dos espaços de moradia e lazer, a criminalidade e a violência que rondam suas casas - o trabalho na infância pode ser um meio de enfrentamento e de proteção à iniquidade social. Diante dessa contingência, pode-se conjeturar que o trabalho precoce, nesses casos, é uma forma de enfrentamento que as famílias encontram para transpor ou minimizar a vulnerabilidade que lhes é socialmente imposta.

Nesse caso, não há como analisar a vulnerabilidade somente sob o prisma dos riscos do trabalho de catação, mas contemplá-la sob a óptica dos processos sociais. É necessário reconhecer que a exposição aos riscos ocupacionais não deve ser a medida de maior peso para mensurá-la ou dimensioná-la, mas que o ambiente, as percepções, os significados e a capacidade de enfrentamento em relação às adversidades impostas pelas variados processos de exclusão são fatores essenciais para a produção e controle da vulnerabilidade.

Por isso, além do contexto ocupacional e familiar dessas crianças e adolescentes, é imprescindível um olhar que leve em conta a existência e a efetividade da rede de proteção social que circunda essas famílias. Pois essa rede é um espaço de planejamento e de execução de mecanismos de proteção às desigualdades e de inserção em relações de trabalho mais "saudáveis", seja por fiscalização e vigilância, seja no aprimoramento de políticas públicas que possibilitem uma proteção coerente com a realidade locorregional.

Formular políticas de atenção e proteção à criança e ao adolescente significa refletir sob a perspectiva da sua emancipação. Tal como são propostas as ações de promoção, sobretudo aquelas atreladas a variadas modalidades de assistência e assentadas no pressuposto de minimização do problema, contribuem antes para sua reprodução, pois fazem sombra às estratégias de acesso aos direitos de cidadania ativa e promotoras de inclusão social. 


\section{SOCIAL EXCLUSION AND VULNERABILITY IN THE WORK OF CHILD AND ADOLESCENT COLLECTORS OF RECYCLABLE MATERIALS}

ABSTRACT: The aim of this article is to analyze the daily work of child and adolescent collectors of recyclable materials, based on the concepts of vulnerability and social exclusion. It is a qualitative study involving major institutional players engaged in social, legal, and support actions, in addition to a group of children, adolescents, and their families, from the city of Chapecó, in the state of Santa Catarina. We conclude that the collection of recyclable material is a form of social integration that, at the same time, exposes children and adolescents to risks of all kinds, forming a process of vulnerability in these age groups.

KEYwords: Social Exclusion. Vulnerabilities. Child labor. Recyclable material collectors.

\section{EXCLUSIÓN SOCIAL Y VULNERABILIDAD EN EL TRABAJO DE LOS NIÑOS Y ADOLESCENTES CATADORES DE MATERIAL RECICLABLE}

RESUMEN: El objetivo de este artículo es analizar el cuotidiano del trabajo de los niños y adolescentes catadores de materiales reciclables, basada en los conceptos de vulnerabilidad y exclusión social. Se trata de un estudio cualitativo con la participación importantes actores institucionales involucrados en acciones sociales, jurídicas y de apoyo, y también con un grupo de niños y adolescentes y sus familias en la ciudad de Chapecó, estado de Santa Catarina. Llegamos a la conclusión de que el trabajo de recoger el material reciclable constituye una forma de integración social, que mientras, expone a los niños y adolescentes en situación de riesgo de todos los tipos, construyendo procesos de vulnerabilidad en estos grupos de edad.

Palabras ClaVe: Exclusión social.Vulnerabilidades. Trabajo infantil. Catadores de material reciclable. 


\section{REFERÊNCIAS}

AYRES, J. R.; FRANÇA, I.; CALAZANS, G.; SALLETTI, H. Vulnerabilidade e prevenção em tempos de Aids. In: BARBOSA, R.; PARKER, R. Sexualidade pelo avesso: direitos, identidades e poder. Rio de Janeiro: Relume Dumará; 1999. p. 49-79.

AYRES, J. R.; FRANÇA, I.; CALAZANS, G.; SALLETTI, H. O Conceito de Vulnerabilidade e as Práticas de Saúde: novas perspectivas e desafios. In: CZERESNIA, D.; FREITAS, C. M. Promoção da Saúde: Conceitos, reflexões, tendências. Rio de Janeiro: Fiocruz, 2003. p. 117-140.

AYRES, J. R.; PAIVA, V.; FRANÇA, I. Conceitos e práticas de prevenção: da história natural da doença ao quadro da vulnerabilidade e direitos humanos. In: PAIVA, V.; AYRES, J. R.; BUCHALLA, C. M. (Org.). Direitos humanos e vulnerabilidade na prevenção e promoção da saúde [Coletânea]. Livro 1: Da doença à cidadania. Curitiba: Juruá, 2012. p. 71-94.

BARDIN L. Análise de conteúdo. Lisboa: Edições 70, 2009.

BOSI, A. de P. A organização capitalista do trabalho "informal": o caso dos catadores de recicláveis. Rev. Bras. Ciência. Social., São Paulo, v. 23, n. 67, p. 101-116, Jun. 2008.

CASTEL, R. As metamorfoses da questão social: uma crônica do salário. Petrópolis: Vozes, 1998.

CAVALCANTE, S.; FRANCO, M. F. A. Profissão perigo: percepção de risco à saúde entre os catadores do Lixão do Jangurussu. Rev. Mal-Estar Subj., Fortaleza, v. 7, n. 1, p. 211 231, mar. 2007.

ESCOREL, S. Vidas ao léu: trajetórias de exclusão social. Rio de Janeiro: Fiocruz, 1999.

FACCHINI, L.; FASSA, A.; AGNOL, M.; MAIA, M.. Trabalho infantil em Pelotas: perfil ocupacional e contribuição à economia. Ciênc. saúde coletiva, São Paulo, v. 8, n. 4, p. $953-$ 961, 2003.

KASSOUF, A. L. O que conhecemos sobre o trabalho infantil? Nova econ., Belo Horizonte, v. 17, n. 2, p. 323-350, ago. 2007.

LAVINAS, L. Pobreza e exclusão: traduções regionais de duas categorias práticas. $R e$ vista Econômica, Niterói, v. 4, n. 1, p. 25-59, 2003.

MARTINS, J. de S. A sociedade vista do abismo: Novos estudos sobre exclusão, pobreza e classes sociais. 2. ed. Petrópolis, RJ: Vozes, 2003.

MEYER, D.; MELLO, D.; VALADAO, M.; AYRES, J. R. "Você aprende. A gente ensina?" Interrogando relações entre educação e saúde desde a perspectiva da vulnerabilidade. Cadernos de Saúde Pública, Rio de Janeiro, v. 22, n. 6, p. 1335-1342, jun. 2006.

NAKAMURA, E.; EGRY, E.; CAMPOS, C.; NICHIATA, L.; CHIESA, A.; TAKAHASHI, R. The potential of an instrument to identify social vulnerabilities and health needs: col- 
lective health knowledge and practices. Revista Latino-Amaricana de Enfermagem, Ribeirão Preto, v. 17, n. 2, p. 253-258, mar./abr. 2009.

PALMA, A.; MATTOS, U. Contribuições da ciência pós-normal à saúde pública e a questão da vulnerabilidade social. História, Ciências, Saúde-Manguinhos, v. 8, n. 3, p. 567-90, set./dez. 2001.

SAWAIA, B. B. As Artimanhas da Exclusão: uma análise ético-psicossociológica. Rio de Janeiro: Vozes, 1999.

SIERRA, V. M.; MESQUITA, W. A. Vulnerabilidades e fatores de risco na vida de crianças e adolescentes. São Paulo em Perspectiva, São Paulo, v. 20, n. 1, p. 148-155, 2006.

Lucimare Ferraz: Doutora em Ciências da Saúde (Unifesp). Docente do programa stricto sensu em Ciências da Saúde da Unochapeco e do departamento de Enfermagem da UDESC.

E-mail: Iferraz@unochapeco.edu.br

Mara Helena de Andrea Gomes: Doutora em Sociologia Política e Pós-Doc pela École des Hautes Études en Sciences Sociales (Paris, 2002-2003). Professora adjunta da Universidade Federal de São Paulo.

E-mail:maraandrea@unifesp.br

Cássio Silveira: Doutor em Saúde Pública pela Universidade de São Paulo (USP). Professor adjunto e pesquisador do Departamento de Medicina Social da Faculdade de Ciências Médicas da Santa Casa de São Paulo (Programa de Pós-Graduação em Saúde Coletiva); Técnico em Assuntos Educacionais (Disciplina de Epidemiologia, Departamento de Medicina Preventiva) da Universidade Federal de São Paulo. E-mail: cassio@cealag.com.br 